\title{
Duopolistic competition with multiple scenarios and different attitudes towards uncertainty
}

\author{
L. Monroy ${ }^{*}$ M.A. Caraballo ${ }^{\dagger}$ A.M. Mármol ${ }^{\ddagger}$
}

\begin{abstract}
In this paper we address duopolistic competition when the firms have to assess the results of the interaction at different scenarios. Specifically we consider the case in which the scenarios are identified with several states of nature and, therefore, the firms face uncertainty on their results. The probability of occurrence of the scenarios is unknown by the firms and they make their output decision before uncertainty is resolved. Within this framework, we analyze competition between firms when these firms exhibit extreme and neutral attitudes towards uncertainty with respect to the final profits. For the variety of cases that can occur, we characterize the sets of equilibria, and provide procedures to determine them. The analysis proposed can also be applied to study situations in a deterministic setting with simultaneous multiple scenarios, and to the analysis of multiple criteria duopolistic competition.
\end{abstract}

Keywords: Game theory, multi-scenario games, Cournot duopoly, equilibria. JEL classification: D43, D81, L10

\section{Introduction}

In this paper, we investigate a model of duopolistic competition where firms face different market demands at several possible scenarios or states of nature. Only

\footnotetext{
${ }^{*}$ Corresponding author. Dpto. de Economía Aplicada III and IMUS. Universidad de Sevilla, Spain.lmonroy@us.es.

†Dpto. de Economía e Historia Económica, Universidad de Sevilla, Spain. mcaraba@us.es.

${ }^{\ddagger}$ Dpto. de Economía Aplicada III and IMUS. Universidad de Sevilla, Spain. amarmol@us.es.
} 
one will be realized as the true state, and no information is available about the probability distributions of the occurrence of these states. Specifically, we analyze the extension of a Cournot duopoly (Cournot, 1838) in which two firms producing homogeneous products have to deal with uncertain demand and may show different attitudes towards uncertainty.

Approaches based on subjective expected utility (Savage, 1954) could primarily be used to address the identification of equilibria in a multiple scenario context. When firms seek to maximize their expected profits with subjective probabilities distributions, equilibrium outcomes are strongly determined by the vectors of probabilities. However, in the strategic situations studied in this paper, uncertainty on the probability distributions and attitudes of the firms with respect to risk are relevant issues which cannot be easily accommodated in the theory of expected utility.

Other analysis of duopoly games where firms act under uncertainty can be found in the literature. One line of research investigates incentives for duopolists to share their private information about market uncertainty with its competitors. For instance, Novshek and Sonnenschein (1982), Vives (1984), Li (1985), Gal-Or (1986), among others, analyzed how market uncertainty with either unknown market demand or unknown constant marginal cost affects firm's behavior. More recently, $\mathrm{Wu}$ et al. (2008) address a Cournot model with capacity constraints, in which the uncertainty is about uncertain demand conditions or production costs.

Related work on oligopolistic competition under uncertainty have focused on the conditions for the existence of equilibria and their properties, in an effort to provide a general and tractable framework for the analysis of quantity competition under demand uncertainty. In this line of research, Eichberger and Kelsey (2002), analyzed the effect of ambiguity in symmetric n-player games with aggregate externalities. The application of their results to a Cournot oligopoly showed that the total output in these models is lower when there is uncertainty. Lagerlöf (2007) obtains the conditions on distribution functions of the stochastic demand intercept that guarantee the existence of a unique equilibrium in a linear framework, while Einy et al. (2010) show some examples in which a (Bayesian) Cournot equilibrium in pure strategies may not exist when firms have incomplete information about demand and costs. Moreover, they provide sufficient conditions for existence and uniqueness of Cournot equilibria in a certain class of industries. De Frutos and Fabra (2011) and Lepore (2012) consider two-stage games to analyze competition between firms in which firms make capacity investments under demand uncertainty prior to competing in prices. 
The majority of these papers have assumed that firms are risk neutral. Nevertheless, evidence shows that in the presence of uncertainty, firms often exhibit different risk attitudes. The incorporation of these rational, but uncertain, beliefs will certainly influence the outcomes of the decision processes. This issue has been analysed by Asplund (2002), who studied competition in prices and quantities between risk-averse firms. Fontini (2005) analyzed a Cournot oligopoly under uncertainty using the Choquet expected utility model (Schmeilder, 1989) with optimistic and pessimistic firms, and showed that when uncertainty is low, optimistic firms make higher profits than pessimistic firms, and when uncertainty is high, only optimistic firms participate in the market producing too much and facing losses. Eichberger et al. (2009) also addressed ambiguity in strategic games. In their model, uncertainty is defined over the other players' actions. Formally, individuals partially distrust their own beliefs about other players' behavior and place themselves in the best and worst cases depending on their relative optimism and pessimism. In a recent paper, Chronopoulos et al. (2014) analyze the impact of risk aversion and uncertainty on the optimal investment timing decision in a duopolistic competition. They consider the case where the two competing firms exhibit the same level of risk aversion.

In the above mentioned papers, uncertainty is analysed by means of a random variable in the corresponding parameter of the model or by considering a probability distribution on the state of nature, and expected utility theory is applied then in order to make decisions. By contrast, we develop our study in a context where the probabilities of occurrence of these states cannot be ascertained by firms. Our approach is essentially based on the idea that uncertainty cannot be modeled globally for every action of one of the firms. Due to the strategic interdependence of the environment in which firms make their decisions, a firm's best strategy not only depends on the strategy adopted by the other firm, but also on the performance of the profits in the scenarios.

In our setting, the firms face a different market demand in each of the two scenarios. The profits of the firms depend on the scenario that will occur, and the firms' attitudes to uncertainty are defined with respect to the profits in each possible scenario. In our model firms have to make their output decision before uncertainty is resolved, and, contrarily to the subjective expected utility approach, it is assumed that no information exists on the probability of occurrence of the different states.

In order to describe the reaction functions of the firms in the multiple scenario framework, we need to take into account the different attitudes towards uncertainty that they may exhibit. In the situations we investigate, such attitudes are explained 
by the importance that each firm gives to the realization of profits: a firm is conservative if it gives relatively greater importance to the scenario with low profits, the reverse is true for optimistic firms. More precisely, we investigate the situations in which these attitudes represent the extreme cases, i.e., conservative firms which only take into account the scenario that implies the lowest profit, and optimistic firms which only consider the scenario with the highest profit. We also consider the case of neutral firms which have a similar concern about both scenarios.

It is worth remarking that subjective expected utility approaches are limited to the cases in which all the firms are expected profit maximizers. Our model generalizes the representation of their preferences by allowing also the possibilities that firms are minimum (maximum) profit maximizers. Our representation of conservative preferences can be considered a special case of Gilboa and Schmeidler's (1989) maxmin expected utility model in which all the probability distributions are possible, whereas the neutral attitude of the firms is identified with the maximization of expected utility when all the scenarios are equally probable.

In this paper we present an analysis of the different competitive situations that can arise. That is, we study the cases in which both firms have the same attitude to uncertainty, and the cases in which this attitude is different. In Caraballo et al. (2015), we analyzed duopolistic competitions under uncertainty in which demand functions are linear and the firms exhibit identical extreme attitudes towards uncertainty. Now, we extend and complete the investigation of strategic competition between firms in a multiple scenario framework.

The main contributions in this new paper are: Firstly, we extend the analysis to strategic competition in which the firms deal with general demand functions. This new context is more complex, since some of the desirable and well-known properties of linear functions are lost. We investigate to what extent the results for linear demands are also valid in the general case. Secondly, we address the cases in which the firms do not show the same attitude towards uncertainty. The analysis of these models becomes more complicated as a consequence of the lack of symmetry, and this is the reason of the scarcity of results in the existing literature. However, our results on duopoly models under uncertainty with asymmetric firms provides more accurate insights into Cournot competition. Overall, we present an unified framework for the exhaustive analysis of the different cases.

Our first result is the identification of the reaction functions for conservative, optimistic, and neutral firms in terms of the reaction functions at each scenario. On the basis of these reaction functions we characterize the equilibria for several specific 
situations: both firms are conservative, both firms are optimistic, both firms are neutral, and the mixing between the three types of previous firms. We state that for the cases in which firms show the same attitude to uncertainty, equilibria always exist, and general procedures to determine them are provided. In the cases in which the attitude to uncertainty of the firms does not coincide, the existence of equilibria cannot always be assured. Nevertheless, we provide sufficient conditions for the existence of equilibria, together with results that permit the identification of the set of equilibria.

The methodological framework considered in this paper can also be applied to other decisional contexts in which the utilities of the firms are represented by vectorvalued functions. These contexts include Cournot games in which the profits of the firms are evaluated simultaneously in different scenarios. For instance, these scenarios can be several geographical regions, or different types of consumers. Another kind of problem in which the analysis proposed can be helpful is multi-criteria Cournot games. In these models, firms regard several conflicting criteria at the same time. For example, social responsible firms take into account not only their profits, but also a share of consumer surplus, and this additional goal may heavily influence the equilibrium outcomes. Related work about multi-criteria strategic models is Mármol et al. (2016) and Monroy et al. (2016).

The rest of the paper is organized as follows. In Section 2 we present the model. The reaction functions for conservative, optimistic and neutral firms are established in Section 3. In Section 4 the notion of equilibrium with attitude to uncertainty is stated. Sections 5 and 6 are devoted to the analysis of the equilibria when firms have identical attitude to uncertainty and different attitude to uncertainty, respectively. Section 7 contains the conclusions of this research. In order to simplify the presentation, proofs are included in an Appendix.

\section{Two-scenario Cournot games}

We consider a duopoly situation in which two firms producing homogeneous commodities compete in quantities and face uncertain market demand since two different future scenarios are possible. In scenario $k, k=1,2$, the inverse demand function is given by $p=P_{k}(Q)$, where $Q$ is the total quantity produced in the market. As it is standard in the literature (see for instance, Kreps and Scheinkman(1983)), we assume that each function $P_{k}(Q)$ is twice-continuously differentiable, strictly 
decreasing, concave and non-negative on some bounded interval $\left(0, Q_{k}\right)$, and that $P_{k}(Q)=0$ for $Q \geq Q_{k}$.

In order to avoid trivial cases, we assume that the profit function of one of the scenarios does not dominate the other. For the sake of simplicity in the presentation, we also assume that the demand functions only intersect once. Thus, we consider that the reservation price in the first scenario, $P_{1}(0)$, is higher than that of the second, $P_{2}(0)$, and the perfect competition quantity at scenario 1 is smaller than the perfect competition quantity at scenario 2. By dropping this assumption, we could face a situation in which the demand functions intersect twice. An extended analysis based on the same ideas as those presented here could be performed for these cases.

Firms $i=1,2$ are allowed to select any non-negative quantity $q^{i}$. Since the demand is bounded, the strategy set of each firm is given by a bounded convex set $A^{i} \subseteq[0, \infty), i=1,2$.

For simplicity, it is assumed that firms have no fixed costs and their marginal costs are equal to zero. In addition, we consider that the reservation price and market size are finite. Thus, for $i=1,2$, the profit for firm $i$ at scenario $k$ is: $\Pi_{k}^{i}\left(q^{1}, q^{2}\right)=q^{i} P_{k}\left(q^{1}+q^{2}\right)$, and the two-scenario Cournot game is represented as $G=\left\{\left(A^{i}, \Pi_{1}^{i}, \Pi_{2}^{i}\right)_{i=1,2}\right\}$.

Note that in each scenario, the profit function of each firm is strictly concave in its own action. As a consequence, given the action of one of the firms in the corresponding interval $\left(0, Q_{k}\right)$, the profit of the other attains its maximum where its derivative is null. For $q^{j} \in\left(0, Q_{k}\right)$, the reaction function of firm $i$ to the action of firm $j$ at scenario $k$, denoted by $r_{k}^{i}\left(q^{j}\right)$, is implicitly defined by the following equation.

$$
P_{k}\left(q^{1}+q^{2}\right)+q^{i} P_{k}^{\prime}\left(q^{1}+q^{2}\right)=0
$$

For $q^{j} \geq Q_{k}$, the reaction function is defined as $r_{k}^{i}\left(q^{j}\right)=0$. Under our initial assumptions on the inverse demand functions, the reaction functions at each scenario, $r_{k}^{i}$, are non-increasing, strictly decreasing over the range where it is strictly positive, and continuously differentiable (see, for instance, Kreps and Scheikman, 1983). Moreover, these assumptions guarantee the existence of a unique Cournot equilibrium at each scenario.

In our analysis the different attitudes towards uncertainty are modeled by means of a value function which represents the firm's evaluation of the profits attained in both scenarios when the different strategies are adopted. We will investigate the 
cases in which firms are conservative, optimistic and neutral. A conservative firm follows the extreme maxmin utility decision rule that prescribes concentrating on the state with the lower profit. An optimistic firm evaluates its profit assuming the occurrence of the higher-profit state. A neutral firm considers the average between both extreme evaluations.

The corresponding value functions for the different types of firms are respectively:

$$
\begin{aligned}
\Pi_{c}^{i}\left(q^{1}, q^{2}\right) & =\operatorname{Min}\left\{\Pi_{1}^{i}\left(q^{1}, q^{2}\right), \Pi_{2}^{i}\left(q^{1}, q^{2}\right)\right\} \\
\Pi_{o p}^{i}\left(q^{1}, q^{2}\right) & =\operatorname{Max}\left\{\Pi_{1}^{i}\left(q^{1}, q^{2}\right), \Pi_{2}^{i}\left(q^{1}, q^{2}\right)\right\} \\
\Pi_{n}^{i}\left(q^{1}, q^{2}\right) & =\frac{1}{2}\left(\Pi_{c}^{i}\left(q^{1}, q^{2}\right)+\Pi_{o p}^{i}\left(q^{1}, q^{2}\right)\right) .
\end{aligned}
$$

\section{$3 \quad$ Reaction functions with attitudes to uncertainty}

Under our initial assumptions on the demand functions, for positive values of $P$ and $Q$, the inverse demand functions of the scenarios intersect at only one point. Denote by $\bar{Q}$ the point such that $P_{1}(\bar{Q})=P_{2}(\bar{Q})$, and note that for values of $Q$ below $\bar{Q}$, the price in scenario 2 is lower than the price in scenario 1.

Thus, if firm $i$ is conservative, then the value function is:

$$
\Pi_{c}^{i}\left(q^{1}, q^{2}\right)= \begin{cases}\Pi_{2}^{i}\left(q^{1}, q^{2}\right) & \text { if } q^{1}+q^{2} \leq \bar{Q} \\ \Pi_{1}^{i}\left(q^{1}, q^{2}\right) & \text { if } q^{1}+q^{2} \geq \bar{Q}\end{cases}
$$

If firm $i$ is optimistic, then the value function is:

$$
\Pi_{o p}^{i}\left(q^{1}, q^{2}\right)= \begin{cases}\Pi_{1}^{i}\left(q^{1}, q^{2}\right) & \text { if } q^{1}+q^{2} \leq \bar{Q} \\ \Pi_{2}^{i}\left(q^{1}, q^{2}\right) & \text { if } q^{1}+q^{2} \geq \bar{Q}\end{cases}
$$

If firm $i$ is neutral, then the value function coincides with the average utility. Thus, it can be written as:

$$
\Pi_{n}^{i}\left(q^{1}, q^{2}\right)=\frac{1}{2}\left(\Pi_{1}^{i}\left(q^{1}, q^{2}\right)+\Pi_{2}^{i}\left(q^{1}, q^{2}\right)\right) .
$$

Both the value function of the conservative firm and the value function of the optimistic firm are continuous in the strategy space of the firms. However, note that they are not differentiable at the points in which $q^{1}+q^{2}=\bar{Q}$.

Denote by $L$ the line representing a total quantity equal to $\bar{Q}$,

$$
L=\left\{\left(q^{1}, q^{2}\right) \in \mathbb{R}^{2} \mid q^{1}+q^{2}=\bar{Q}\right\} .
$$


This line plays a central role in the analysis presented in this paper, since it partitions the space of strategies of the firms into two regions, $\underline{L}, \bar{L}$, in which the profit function of one or the other scenario applies.

The relative position of this line and the curves representing the reaction function of the firm at each scenario determines a piece-wise reaction function for the pessimistic firm, and also a piecewise reaction function for the optimistic firm. The derivatives of the reaction functions in each scenario verify $\left(r_{k}^{i}\right)^{\prime}\left(q^{j}\right) \geq-1$, for $k=1,2, i=1,2$, with strict inequality for $q^{j}$ such that $r_{k}^{i}\left(q^{j}\right)>0$ (see Kreps and Scheinkman, 1983, Lemma 1, p. 328). The slope of the line $L$ is equal to -1 . As a consequence, the line intersects each one of the reaction functions at most at one point.

In what follows, we assume that the inverse demand functions in the scenarios are such that $r_{1}^{i}\left(q^{j}\right) \leq r_{2}^{i}\left(q^{j}\right)$ for all $q^{j} \in A^{j}, i, j=1,2, i \neq j$. This assumption is not very restrictive. In fact, it is adopted in the general treatment proposed by Kreps and Scheinkman (1983), and it holds for a wide range of demand functions, including linear and quadratic demand functions, among others.

The following result describes the reaction function of a conservative firm, denoted by $R_{c}^{i}$.

Lemma 3.1. If firm $i$ is conservative, then the reaction function, $R_{c}^{i}$, is given by:

$$
R_{c}^{i}\left(q^{j}\right)=\left\{\begin{array}{lll}
r_{1}^{i}\left(q^{j}\right) & \text { for } & \bar{Q}-q^{j} \leq r_{1}^{i}\left(q^{j}\right) \leq r_{2}^{i}\left(q^{j}\right) \\
\bar{Q}-q^{j} & \text { for } & r_{1}^{i}\left(q^{j}\right) \leq \bar{Q}-q^{j} \leq r_{2}^{i}\left(q^{j}\right) \\
r_{2}^{i}\left(q^{j}\right) & \text { for } \quad r_{1}^{i}\left(q^{j}\right) \leq r_{2}^{i}\left(q^{j}\right) \leq \bar{Q}-q^{j}
\end{array}\right.
$$

That is to say, the reaction function for a conservative firm $i$ is a piecewise continuous function, which coincides with the reaction function corresponding to scenario 1 for those strategies of firm $j$ such that the total quantity offered when firm $i$ reacts with his best response at scenario 1 is greater than $\bar{Q}$. It coincides with the reaction function corresponding to scenario 2 for those strategies of firm $j$ such that the total quantity offered when firm $i$ reacts with his best response at scenario 2 is below $\bar{Q}$. Otherwise, the best response of firm $i$ makes the total quantity offered equal to $\bar{Q}$. It is worth remarking that, since the reaction function at each scenario intersects $L$ at most at one point, then the piecewise conservative reaction function is formed by at most three pieces.

Figure 1 is an illustration of the reaction function for a conservative firm. 


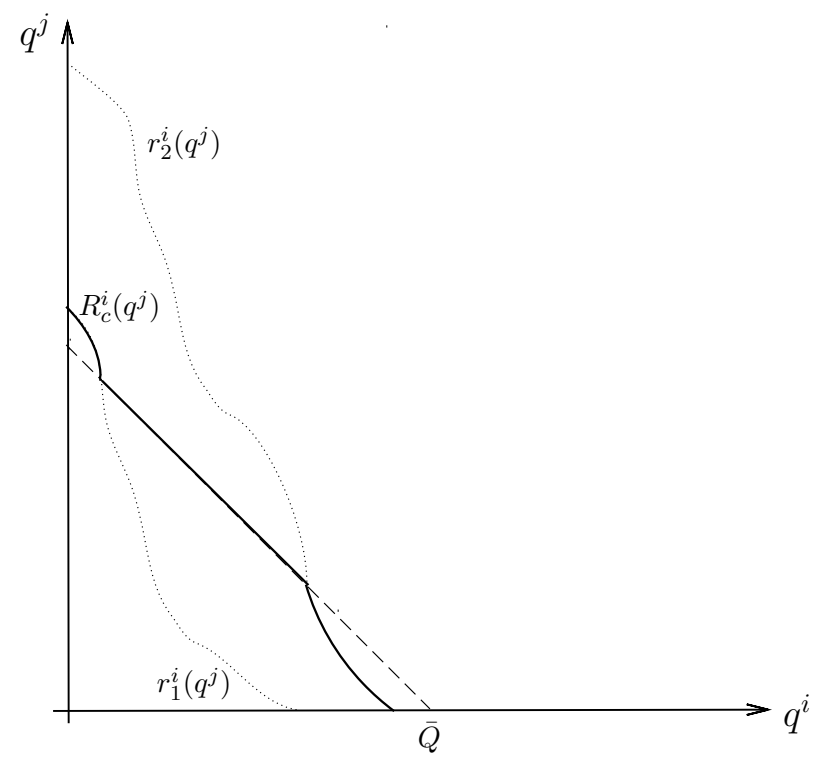

Figure 1: The reaction function of a conservative firm.

The reaction function for an optimistic firm $i$ is denoted by $R_{o p}^{i}$. The following lemma establishes that if the total quantity offered with the pair of strategies obtained with $q^{j}$ and the reaction of firm $i$ at scenario 1 is above $\bar{Q}$, then the reaction of an optimistic firm coincides with the reaction function at scenario 2. Similarly, if the total quantity offered with the pair of strategies obtained with $q^{j}$ and the reaction of firm $i$ at scenario 2 is below $\bar{Q}$, then the reaction of an optimistic firm coincides with the reaction function in scenario 1 .

Lemma 3.2. If firm $i$ is optimistic, then

a) If $\bar{Q}-q^{j} \leq r_{1}^{i}\left(q^{j}\right) \leq r_{2}^{i}\left(q^{j}\right)$, then $R_{o p}^{i}\left(q^{j}\right)=r_{2}^{i}\left(q^{j}\right)$.

b) If $\bar{Q}-q^{j} \geq r_{2}^{i}\left(q^{j}\right) \geq r_{1}^{i}\left(q^{j}\right)$, then $R_{o p}^{i}\left(q^{j}\right)=r_{1}^{i}\left(q^{j}\right)$.

The reaction of firm $i$ for values of $q^{j}$ such that $r_{1}^{i}\left(q^{j}\right) \leq \bar{Q}-q^{j} \leq r_{2}^{i}\left(q^{j}\right)$, still remains to be established. For these values of $q^{j}$, the best response of firm $i$ is either $r_{1}^{i}\left(q^{j}\right)$ or $r_{2}^{i}\left(q^{j}\right)$. If the best response in the first scenario, $r_{1}^{i}\left(q^{j}\right)$, is chosen, then under the first scenario the profit would be $r_{1}^{i}\left(q^{j}\right) P_{1}\left(r_{1}^{i}\left(q^{j}\right)+q^{j}\right)$. If $r_{2}^{i}\left(q^{j}\right)$ is selected, then under the second scenario the profit would be $r_{2}^{i}\left(q^{j}\right) P_{2}\left(r_{2}^{i}\left(q^{j}\right)+q^{j}\right)$. An optimistic firm will select the best response that yields the highest profit.

The values of $q^{j}$ for which the profit obtained in scenario 1 with the best response in scenario 1 coincides with the profit in scenario 2 with the best response in scenario 
2 are the values for which this firm switches from one of the best responses to the other. These values are the solutions to the equation:

$$
r_{1}^{i}\left(q^{j}\right) P_{1}\left(r_{1}^{i}\left(q^{j}\right)+q^{j}\right)=r_{2}^{i}\left(q^{j}\right) P_{2}\left(r_{2}^{i}\left(q^{j}\right)+q^{j}\right)
$$

That is, to say

$$
\Pi_{1}^{i}\left(r_{1}^{i}\left(q^{j}\right), q^{j}\right)=\Pi_{2}^{i}\left(r_{2}^{i}\left(q^{j}\right), q^{j}\right) .
$$

Let $S$ be the set of positive solutions of this equation, $S=\left\{s_{t}\right\}_{t=1, \ldots \bar{t}}$, and set $s_{0}=0$, and $s_{\bar{t}+1}=+\infty$.

Note that $\Pi_{1}^{i}\left(r_{1}^{i}\left(q^{j}\right), q^{j}\right), \Pi_{2}^{i}\left(r_{2}^{i}\left(q^{j}\right), q^{j}\right)$ are continuous as functions of $q^{j}$, and that the solutions of this equation are the points at which the reaction function, $R_{o p}^{i}$, switches from the reaction function in one scenario to the reaction function in the other scenario. Thus, these are the only points in which $R_{o p}^{i}$ can be discontinuous.

The description of the reaction function of an optimistic firm $i, R_{o p}^{i}$, depends on which of the best responses of the scenarios applies at $q^{j}=0$. In both scenarios, the best response of firm $i$, when the strategy of firm $j$ is $q^{j}=0$, is the monopoly quantity $q_{M_{k}}$, and therefore, $\Pi_{k}^{i}\left(r_{k}^{i}(0), 0\right)=\Pi_{k}^{i}\left(q_{M_{k}}, 0\right)$. If $\Pi_{1}^{i}\left(q_{M_{1}}, 0\right)>\Pi_{2}^{i}\left(q_{M_{2}}, 0\right)$ then $R_{o p}^{i}(0)=r_{1}^{i}(0)$. Analogously, if $\Pi_{1}^{i}\left(q_{M_{1}}, 0\right)<\Pi_{2}^{i}\left(q_{M_{2}}, 0\right)$ then $R_{o p}^{i}(0)=r_{2}^{i}(0)$. Note that $\Pi_{k}^{i}\left(q_{M_{k}}, 0\right)$ represents the monopoly profit at scenario $k$, which is the maximum profit attainable under that specific scenario.

Thus, in order to describe the reaction function, we consider two cases, as established in the following lemma.

Lemma 3.3. If firm $i$ is optimistic, the following hold:

a) If $\Pi_{1}^{i}\left(q_{M_{1}}, 0\right)>\Pi_{2}^{i}\left(q_{M_{2}}, 0\right)$, then

$$
R_{o p}^{i}\left(q^{j}\right)=\left\{\begin{array}{l}
r_{1}^{i}\left(q^{j}\right) \quad \text { if } s_{t} \leq q^{j}<s_{t+1}, \text { with an even } t \\
r_{2}^{i}\left(q^{j}\right) \quad \text { if } s_{t} \leq q^{j}<s_{t+1}, \text { with an odd } t
\end{array}\right.
$$

b) If $\Pi_{1}^{i}\left(q_{M_{1}}, 0\right)<\Pi_{2}^{i}\left(q_{M_{2}}, 0\right)$

$$
R_{o p}^{i}\left(q^{j}\right)=\left\{\begin{array}{l}
r_{1}^{i}\left(q^{j}\right) \quad \text { if } s_{t} \leq q^{j}<s_{t+1}, \text { with an odd } t \\
r_{2}^{i}\left(q^{j}\right) \quad \text { if } s_{t} \leq q^{j}<s_{t+1}, \text { with an even } t .
\end{array}\right.
$$

Note that if $\bar{Q} \geq r_{2}^{i}(0) \geq r_{1}^{i}(0)$, then it follows from Lemma 3.2 that $R_{o p}^{i}(0)=$ $r_{1}^{i}(0)$, and case a) of the lemma holds. If $r_{1}^{i}(0) \leq \bar{Q} \leq r_{2}^{i}(0)$ then, either cases a) or b) can occur. 


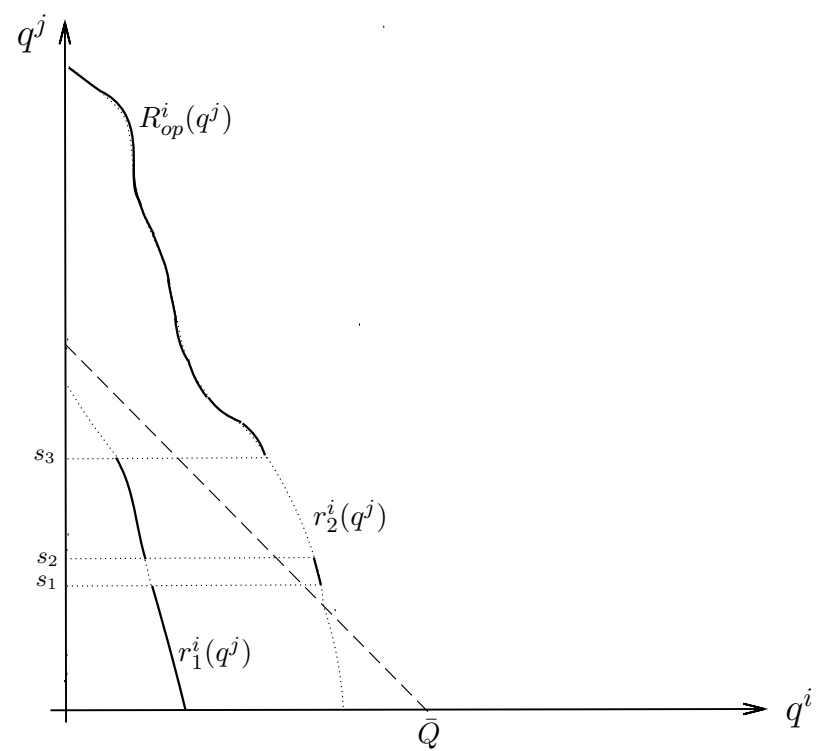

Figure 2: The reaction function of an optimistic firm.

Figure 2 illustrates the reaction function of an optimistic firm. Note that the result does not guarantee the uniqueness of the solution of Equation 3.1 in each interval.

For the case of a neutral firm, the value function is

$$
\Pi_{n}^{i}\left(q^{1}, q^{2}\right)=\frac{1}{2}\left(\Pi_{1}^{i}\left(q^{1}, q^{2}\right)+\Pi_{2}^{i}\left(q^{1}, q^{2}\right)\right) .
$$

It follows from our initial assumptions that the value function for the neutral firm is differentiable and strictly concave in its own action, and the corresponding reaction function is strictly decreasing and continuously differentiable. Moreover, the reaction function of a neutral firm is always in the region bounded by the reaction function in each scenario as stated formally in the next result.

Lemma 3.4. If firm $i$ is neutral, then the reaction function, $R_{n}^{i}$, is non-increasing, strictly decreasing and continuously differentiable in some bounded interval. Moreover, it verifies $r_{1}^{i}\left(q^{j}\right) \leq R_{n}^{i}\left(q^{j}\right) \leq r_{2}^{i}\left(q^{j}\right)$ for all $q^{j} \in A^{j}, i, j=1,2, i \neq j$.

Figure 3 is an illustration of the reaction function of a neutral firm.

\section{Equilibria with attitudes to uncertainty}

In our analysis the different attitudes towards uncertainty are modeled by means of a value function which represents the firm's evaluation of the profits attained in 


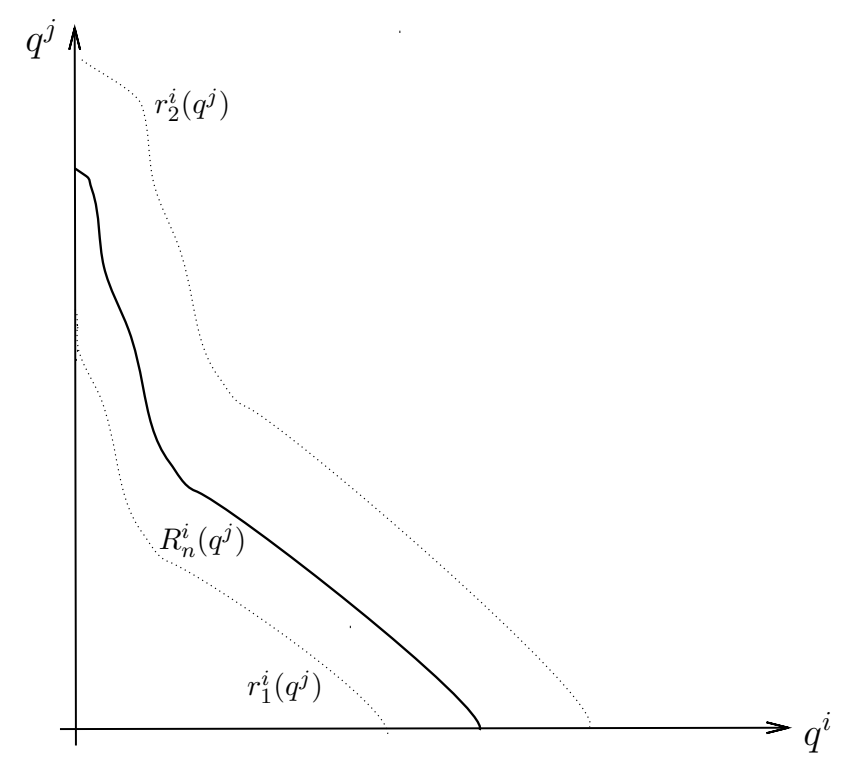

Figure 3: The reaction function of a neutral firm.

both scenarios when the different strategies are adopted.

In general, for $i=1,2$, the attitude towards uncertainty of firm $i$ is represented by a function $u^{i}: \mathbb{R}^{2} \rightarrow \mathbb{R}$, fulfilling:

a) $u^{i}$ is non-decreasing in each of its arguments.

b) $u^{i}\left(y_{1}, y_{2}\right)>u^{i}\left(x_{1}, x_{2}\right)$ whenever $y_{1}>x_{1}$ and $y_{2}>x_{2}$.

For $\left(q^{1}, q^{2}\right) \in A^{1} \times A^{2}$, denote $\Pi_{u^{i}}^{i}\left(q^{1}, q^{2}\right)=u^{i}\left(\Pi_{1}^{i}\left(q^{1}, q^{2}\right), \Pi_{2}^{i}\left(q^{1}, q^{2}\right)\right)$.

The notion of Nash equilibrium (Nash, 1951) when firms exhibit different attitudes to uncertainty can now be stated.

Definition 4.1. $\left(q^{* 1}, q^{* 2}\right)$ is an equilibrium for the two-scenario Cournot game $G=\left\{\left(A^{i}, \Pi_{1}^{i}, \Pi_{2}^{i}\right)_{i=1,2}\right\}$ in which the attitude towards uncertainty of the firms is represented by $u=\left(u^{1}, u^{2}\right)$, if for each $q^{1} \in A^{1}, q^{1} \neq q^{* 1}, \Pi_{u^{1}}^{1}\left(q^{1}, q^{* 2}\right) \leq \Pi_{u^{1}}^{1}\left(q^{* 1}, q^{* 2}\right)$ holds, and for each $q^{2} \in A^{2}, q^{2} \neq q^{* 2}, \Pi_{u^{2}}^{2}\left(q^{* 1}, q^{2}\right) \leq \Pi_{u^{2}}^{2}\left(q^{* 1}, q^{* 2}\right)$ holds.

Denote by $E^{u}(G)$ the set of these equilibria.

Equivalently, $E^{u}(G)$ are the equilibria of the standard normal-form game $G_{u}=$ $\left\{\left(A^{i}, \Pi_{u^{i}}^{i}\right)_{i=1,2}\right\}$.

Recall that it is assumed that the inverse demand functions at the scenarios are such that $r_{1}^{i}\left(q^{j}\right) \leq r_{2}^{i}\left(q^{j}\right)$ for all $q^{j} \in A^{j}, i, j=1,2, i \neq j$. Denote by $T$ the following region:

$$
T=\left\{\left(q^{1}, q^{2}\right) \mid r_{1}^{1}\left(q^{2}\right) \leq q^{1} \leq r_{2}^{1}\left(q^{2}\right), r_{1}^{2}\left(q^{1}\right) \leq q^{2} \leq r_{2}^{2}\left(q^{1}\right)\right\}
$$


Lemma 4.2. If, for $i=1,2$, the functions $u^{i}$ fulfills a) and $\left.b\right)$, then the set of equilibria of the two-scenario Cournot game $G$ with respect to $u=\left(u^{1}, u^{2}\right), E^{u}(G)$, is contained in $T$.

\section{Equilibria for symmetric firms}

In this section we analyse the case of symmetric firms, that is, two-scenario Cournot games in which the firms exhibit identical attitude towards uncertainty.

\subsection{Conservative equilibria}

In order to model a duopoly in which both firms are conservative, the value function of the firms is represented by the worst profit obtained in the scenarios. That is, for $i=1,2, u^{i} \equiv c$, with $c\left(x_{1}, x_{2}\right)=\operatorname{Min}\left\{x_{1}, x_{2}\right\}$.

Therefore, a pair of strategies of the firms is a conservative equilibrium for the two-scenario Cournot game, $G$, if it is an equilibrium when the attitude towards uncertainty of both firms is represented by the function $c$. With conservative equilibria, the firms produce quantities such that no individual deviation produces an improvement in the minimum profit. We denote by $E^{c}(G)$ the set of conservative equilibria of game $G$.

Equivalently, a conservative equilibrium for the two-scenario Cournot game $G$ is an equilibrium for the standard normal-form game, $G_{c}=\left\{\left(A^{i}, \Pi_{c}^{i}\right)_{i=1,2}\right\}$.

As a consequence of the concavity in its own action of the conservative value function, the existence of conservative equilibria is assured under our assumptions. However, since strict concavity fails, multiple equilibria may exist. The following results identify these equilibria for the general case.

For $k=1,2$, denote by $\left(c_{k}^{*}, c_{k}^{*}\right)$ the Cournot equilibrium in scenario $k$. The existence and uniqueness of the Cournot equilibrium in each scenario is guaranteed under the initial assumptions. Note that $2 c_{1}^{*} \leq \bar{Q} \leq 2 c_{2}^{*}$ if and only if $T \cap L \neq\{\emptyset\}$.

The following result identifies the conservative equilibria.

Theorem 5.1. The set of conservative equilibria for the two-scenario Cournot game $G=\left\{\left(A^{i}, \Pi_{1}^{i}, \Pi_{2}^{i}\right)_{i=1,2}\right\}$ is given by

a) If $\bar{Q} \leq 2 c_{1}^{*}$, then $E^{c}(G)=\left\{\left(c_{1}^{*}, c_{1}^{*}\right)\right\}$

b) If $2 c_{1}^{*}<\bar{Q}<2 c_{2}^{*}$ then $E^{c}(G)=T \cap L$ 


\section{c) If $\bar{Q} \geq 2 c_{2}^{*}$, then $E^{c}(G)=\left\{\left(c_{2}^{*}, c_{2}^{*}\right)\right\}$}

Note that if $2 c_{1}^{*} \leq \bar{Q} \leq 2 c_{2}^{*}$, then the points in $T \cap L$ are the conservative equilibria. In the cases in which $T \cap L=\{\emptyset\}$, a single conservative equilibrium exists which coincides with either the Cournot equilibrium in one or in the other scenario.

\subsection{Optimistic equilibria}

The other extreme case in terms of uncertainty attitude of the firms is the situation when the two firms select their strategies by only taking into account the best of the results they can obtain. That is, for $i=1,2, u^{i} \equiv o p$, with $o p\left(x_{1}, x_{2}\right)=\operatorname{Max}\left\{x_{1}, x_{2}\right\}$.

A pair of strategies of the firms is an optimistic equilibrium for the two-scenario Cournot game, $G$, if it is an equilibrium when the attitude towards uncertainty of both firms is represented by the function op. We denote by $E^{o p}(G)$ the set of optimistic equilibria of game $G$. Equivalently, an optimistic equilibrium for the two-scenario Cournot game $G$ is an equilibrium for the standard normal-form game, $G_{o p}=\left\{\left(A^{i}, \Pi_{o p}^{i}\right)_{i=1,2}\right\}$

Accordingly, in an optimistic equilibrium firms obtain quantities such that no individual deviation produces an improvement in its maximum profit.

When both firms are optimistic, since the reaction functions of the firms may be discontinuous, the existence of equilibria cannot be assured. However, Roberts and Sonnenschein (1976) showed the existence of a symmetric Cournot equilibrium for $n$ identical firms when the discontinuities of the reaction functions take the form of "upward jumps", that is, if the function is continuous from the right and upper semicontinuous from the left. As a consequence of this result, when only a switch between scenarios occurs, the existence of equilibria is assured. This is the case of linear demand functions as shown in Caraballo et al. (2015).

Conditions for the existence of the optimistic equilibria based on the relationship between regions $T$ and $L$ can now be established.

Note that the optimistic reaction functions of the firms are formed by pieces of the reaction functions at each scenario, therefore the candidates for optimistic equilibria are the points where they intersect. It follows from the symmetry of the model that these points are necessarily the Cournot equilibria at the two scenarios. This fact is formally stated in the following lemma.

Lemma 5.2. If $\left(\bar{q}^{1}, \bar{q}^{2}\right) \in E^{o p}(G)$ then $\left(\bar{q}^{1}, \bar{q}^{2}\right)=\left(c_{1}^{*}, c_{1}^{*}\right)$ or $\left(\bar{q}^{1}, \bar{q}^{2}\right)=\left(c_{2}^{*}, c_{2}^{*}\right)$. 
This result does not guarantee the existence, nor the uniqueness of the equilibrium.

It is also easy to see that when the Cournot equilibria of the two scenarios are both located on the same region of those limited by $L$, then the optimistic equilibria exists and coincides with one of them, as stated in the following lemma.

Lemma 5.3. Let $G=\left\{\left(A^{i}, \Pi_{1}^{i}, \Pi_{2}^{i}\right)_{i=1,2}\right\}$ be a two-scenario Cournot game

a) If $\bar{Q}<2 c_{1}^{*}$, then $E^{o p}(G)=\left\{\left(c_{2}^{*}, c_{2}^{*}\right)\right\}$.

b) If $\bar{Q}>2 c_{2}^{*}$, then $E^{o p}(G)=\left\{\left(c_{1}^{*}, c_{1}^{*}\right)\right\}$.

In the following theorem, we characterize the optimistic equilibria. Let $q_{M_{k}}$ be the monopoly quantity in scenario $k, k=1,2$.

Theorem 5.4. For the two-scenario Cournot game $G=\left\{\left(A^{i}, \Pi_{1}^{i}, \Pi_{2}^{i}\right)_{i=1,2}\right\}$, the following holds:

a) If $\prod_{1}^{i}\left(q_{M_{1}}, 0\right)>\Pi_{2}^{i}\left(q_{M_{2}}, 0\right)$,

$\left(c_{1}^{*}, c_{1}^{*}\right) \in E^{o p}(G)$ if and only if $s_{t} \leq c_{1}^{*} \leq s_{t+1}$ with an even $t$.

$\left(c_{2}^{*}, c_{2}^{*}\right) \in E^{o p}(G)$ if and only if $s_{t} \leq c_{2}^{*} \leq s_{t+1}$ with an odd $t$.

b) If $\Pi_{1}^{i}\left(q_{M_{1}}, 0\right)<\Pi_{2}^{i}\left(q_{M_{2}}, 0\right)$,

$\left(c_{1}^{*}, c_{1}^{*}\right) \in E^{o p}(G)$ if and only if $s_{t} \leq c_{1}^{*} \leq s_{t+1}$ with an odd $t$.

$\left(c_{2}^{*}, c_{2}^{*}\right) \in E^{o p}(G)$ if and only if $s_{t} \leq c_{2}^{*} \leq s_{t+1}$ with an even $t$.

As an illustration, consider the two-scenario Cournot game in which the inverse demand functions in the scenarios are, respectively, $p=20-20 q^{2}$ and $p=3-q$. The conservative equilibria and the optimistic equilibria are obtained by applying Theorem $5.1 \mathrm{~b}$ ) and Theorem $5.4 \mathrm{a}$ ). The situation is represented in Figure 4.

\subsection{Neutral equilibria}

In order to model a duopoly in which both firms are neutral, the value functions of the firms is represented by the average profit. That is, for $i=1,2, u^{i} \equiv n$, with $n\left(x_{1}, x_{2}\right)=1 / 2\left(x_{1}+x_{2}\right)$,

A pair of strategies of the firms is a neutral equilibrium for the two-scenario Cournot game, $G$, if it is an equilibrium when the attitude towards uncertainty of 

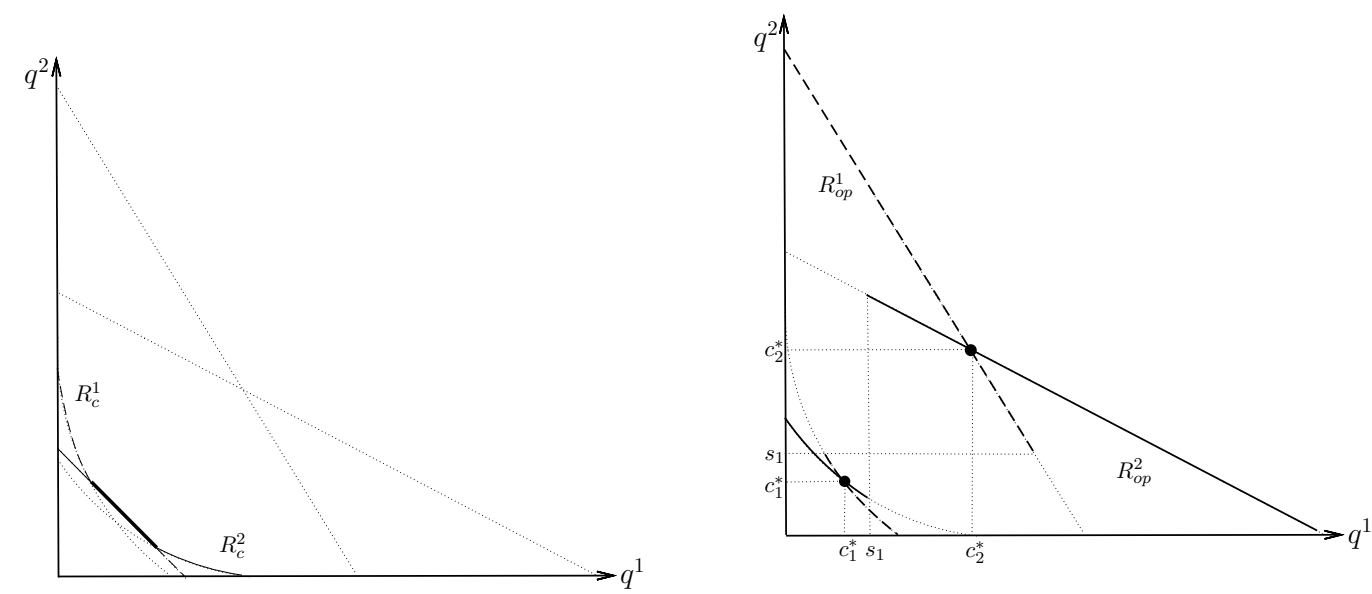

Figure 4: Conservative equilibria (left) and optimistic equilibria (right)

both firms is represented by the function $n$. The set of neutral equilibria of game $G$ is denoted as $E^{n}(G)$. Accordingly, in a neutral equilibrium firms obtain quantities such that no individual deviation produces an improvement in the average profit.

The following result is a consequence of our initial assumptions on the inverse demand functions in the different scenarios, and Lemma 3.4.

Theorem 5.5. For the two-scenario Cournot game, $G=\left\{\left(A^{i}, \Pi_{1}^{i}, \Pi_{2}^{i}\right)_{i=1,2}\right\}, a$ unique neutral equilibrium exists, $\left(c_{n}^{*}, c_{n}^{*}\right)$. Moreover, $c_{1}^{*} \leq c_{n}^{*} \leq c_{2}^{*}$.

\section{$6 \quad$ Hybrid equilibria}

In this section we analyze the case where the firms show different attitudes to uncertainty. In accordance to Definition 4.1, a hybrid equilibrium is an equilibrium of the two-scenario Cournot game, $G$, when the attitude towards uncertainty of the firms is represented by functions $u^{1}$ and $u^{2}$, with $u^{1} \neq u^{2}$. The corresponding set of hybrid equilibria is then denoted $E^{u^{1}, u^{2}}(G)$.

\subsection{Neutral vs conservative}

When one of the firms is neutral an the other firm is conservative, both value functions are concave in its own action. Therefore, the existence of this type of hybrid equilibrium is guaranteed. In what follows, we prove that, under our assumptions, the equilibrium is unique and a result which identifies the equilibrium is presented. 


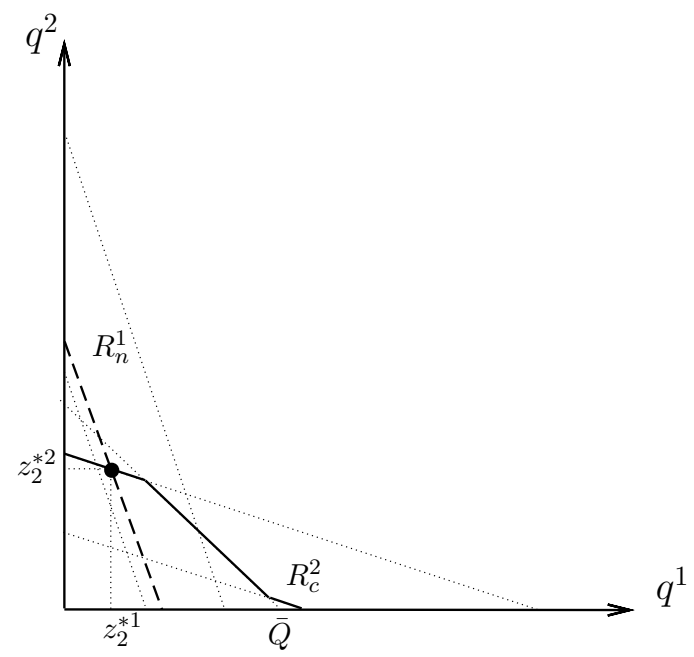

Figure 5: Equilibrium when Firm 1 is neutral and Firm 2 is conservative

Let Firm 1 be neutral and Firm 2 be conservative, then $u^{1} \equiv n$, and $u^{2} \equiv c$. Denote by $\left(z_{k}^{* 1}, z_{k}^{* 2}\right), k=1,2$, the point where the reaction function of firm $1, R_{n}^{1}$, and the reaction function of firm 2 at scenario $k, r_{k}^{2}$, coincide. Denote by $\left(\bar{z}^{1}, \bar{z}^{2}\right)$, the intersection of the graph of the reaction function, $R_{n}^{1}$, and the line $L$. The following theorem establishes the uniqueness of the equilibrium and identifies it, depending on the relative position of the points $\left(z_{k}^{* 1}, z_{k}^{* 2}\right), k=1,2$, and the line $L$.

Theorem 6.1. For the two-scenario Cournot game, $G=\left\{\left(A^{i}, \Pi_{1}^{i}, \Pi_{2}^{i}\right)_{i=1,2}\right\}$, where Firm 1 is neutral and Firm 2 is conservative, an equilibrium always exist and is unique. Moreover,

a) $E^{n, c}(G)=\left(z_{1}^{* 1}, z_{1}^{* 2}\right)$ if and only if $\bar{Q} \leq z_{1}^{* 1}+z_{1}^{* 2}$.

b) $E^{n, c}(G)=\left(z_{2}^{* 1}, z_{2}^{* 2}\right)$ if and only if $\bar{Q} \geq z_{2}^{* 1}+z_{2}^{* 2}$.

c) $E^{n, c}(G)=\left(\bar{z}^{1}, \bar{z}^{2}\right) E^{n, c}(G)$ if and only if $z_{1}^{* 1}+z_{1}^{* 2} \leq \bar{Q} \leq z_{2}^{* 1}+z_{2}^{* 2}$.

As an example, consider the inverse demand function $p=32-50 q$ for scenario 1 , and $p=1-q$ for scenario 2. By applying Theorem $6.1 \mathrm{~b}$ ), the equilibrium is determined. Figure 5 illustrates this situation.

\subsection{Neutral vs optimistic}

When one of the firms is neutral and the other is optimistic, the existence of equilibria is not guaranteed. However, under our assumptions, if an equilibrium exists, it is unique. 
Let Firm 1 be neutral and Firm 2 be optimistic, then $u^{1} \equiv n$, and $u^{2} \equiv o p$. Recall that for $k=1,2,\left(z_{k}^{* 1}, z_{k}^{* 2}\right)$ denotes the point where the reaction function of firm $1, R_{n}^{1}$, and the reaction function of firm 2 at scenario $k, r_{k}^{2}$, coincide. The following result, which follows from Lemma 3.2, states that if an equilibrium exists, it must be either $\left(z_{1}^{* 1}, z_{1}^{* 2}\right)$ or $\left(z_{2}^{* 1}, z_{2}^{* 2}\right)$.

Lemma 6.2. For the two-scenario Cournot game, $G=\left\{\left(A^{i}, \Pi_{1}^{i}, \Pi_{2}^{i}\right)_{i=1,2}\right\}$, where Firm 1 is neutral and Firm 2 is optimistic, at most one equilibrium exists. Moreover,

$$
E^{n, o p}(G) \subset\left\{\left(z_{1}^{* 1}, z_{1}^{* 2}\right),\left(z_{2}^{* 1}, z_{2}^{* 2}\right)\right\}
$$

The following result states the conditions for the existence of a hybrid equilibrium for neutral and optimistic firms, and provides a procedure to identify it. The proof follows analogous reasonings to those of Theorem 5.4 and 6.1.

Theorem 6.3. For the two-scenario Cournot game, $G=\left\{\left(A^{i}, \Pi_{1}^{i}, \Pi_{2}^{i}\right)_{i=1,2}\right\}$, where Firm 1 is neutral and Firm 2 is optimistic,

a) $\left(z_{1}^{* 1}, z_{1}^{* 2}\right) \in E^{n, o p}(G)$ if and only if either a1) or a2) holds

a1) $\Pi_{1}^{2}\left(0, q_{M_{1}}\right)<\Pi_{2}^{2}\left(0, q_{M_{2}}\right)$, and $s_{t} \leq z_{1}^{* 1} \leq s_{t+1}$ with an odd $t$.

a2) $\Pi_{1}^{2}\left(0, q_{M_{1}}\right)>\Pi_{2}^{2}\left(0, q_{M_{2}}\right)$, and $s_{t} \leq z_{1}^{* 1} \leq s_{t+1}$ for an even $t$.

b) $\left(z_{2}^{* 1}, z_{2}^{* 2}\right) \in E^{n, o p}(G)$ if and only if either b1) or b2) holds

b1) $\Pi_{1}^{2}\left(0, q_{M_{1}}\right)<\Pi_{2}^{2}\left(0, q_{M_{2}}\right)$, and $s_{t} \leq z_{2}^{* 1} \leq s_{t+1}$ with an even $t$.

b2) $\Pi_{1}^{2}\left(0, q_{M_{1}}\right)>\Pi_{2}^{2}\left(0, q_{M_{2}}\right)$, and $s_{t} \leq z_{2}^{* 1} \leq s_{t+1}$ for an odd $t$.

Note that in this hybrid situation, the existence of equilibria cannot be guaranteed. For instance, when the inverse demand functions are $p=10-q$ and $p=5-\frac{7}{20} q$, no equilibrium exists, as shown in Figure 6 (left-hand side).

Remark: For the case of linear models, when $\Pi_{1}^{2}\left(0, q_{M_{1}}\right)<\Pi_{2}^{2}\left(0, q_{M_{2}}\right)$, an equilibrium always exists, and is given by $\left\{\left(2 c_{n}^{*}-c_{2}^{*}, 2 c_{2}^{*}-c_{n}^{*}\right)\right\}$. This follows from the fact that, under this condition, the optimistic value function is not discontinuous. This case is illustrated in Figure 6 (right-hand side) for inverse demand functions $p=3-\frac{5}{2} q$, and $p=2-q$. 

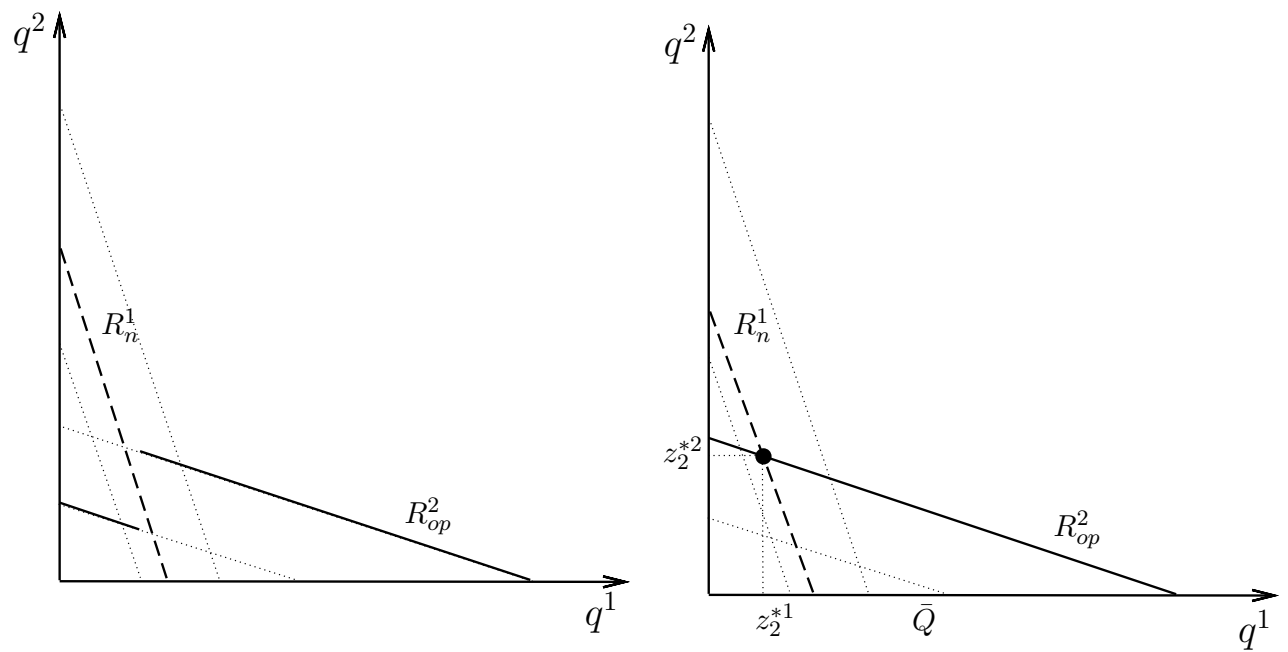

Figure 6: Cases of no equilibrium (left) and equilibrium (right) when Firm 1 is neutral and Firm 2 is optimistic

\subsection{Conservative vs optimistic}

When firms exhibit extreme and opposed uncertainty attitudes, that is, when one of them is conservative and the other is optimistic, the existence of equilibria is not assured either. In what follows we establish conditions for the existence of equilibria in this hybrid situation.

Let Firm 1 be conservative and Firm 2 be optimistic, then $u^{1} \equiv c$, and $u^{2} \equiv o p$.

Denote by $\left(d_{1}^{*}, d_{2}^{*}\right)$ the point where the graph of the reaction function of firm 1 at scenario $1, r_{1}^{1}$, and the graph of the reaction function of firm 2 at scenario $2, r_{2}^{2}$, intersect. This point can be seen as the Cournot equilibrium in a situation where the demand function of firm 1 corresponds to that of scenario 1, and the demand function of firm 2 corresponds to that of scenario 2 . Since the inverse demand functions of the firms are identical at each scenario, it follows that $\left(d_{2}^{*}, d_{1}^{*}\right)$ is the intersection point of the graph of the reaction function of firm 1 at scenario $2, r_{2}^{1}$, and the reaction function of firm 2 at scenario $1, r_{1}^{2}$ (note that $d_{1}^{*}$ or $d_{2}^{*}$ might be null). In addition, we have to consider the points of discontinuity of the reaction function of the optimistic firm. We denote these points as $\left(s_{t}, R_{o p}^{2}\left(s_{t}\right)\right), t=0,1, \ldots \bar{t}$. The following lemma states that if equilibria exist, then they must coincide with some of these points.

Lemma 6.4. For the two-scenario Cournot game, $G=\left\{\left(A^{i}, \Pi_{1}^{i}, \Pi_{2}^{i}\right)_{i=1,2}\right\}$, if Firm 
1 is conservative and Firm 2 is optimistic, then

$$
E^{c, o p}(G) \subset\left\{\left(d_{1}^{*}, d_{2}^{*}\right),\left(d_{2}^{*}, d_{1}^{*}\right),\left(s_{t}, R_{o p}^{2}\left(s_{t}\right)\right), t=0,1, \ldots \bar{t}\right\}
$$

In the following result these hybrid equilibria are identified in the different cases.

Theorem 6.5. For the two-scenario Cournot game, $G=\left\{\left(A^{i}, \Pi_{1}^{i}, \Pi_{2}^{i}\right)_{i=1,2}\right\}$, where Firm 1 is conservative and Firm 2 is optimistic.

a) $\left(s_{t}, R_{o p}^{2}\left(s_{t}\right)\right) \in E^{c, o p}(G)$ if and only if $\bar{Q}=s_{t}+R_{o p}^{2}\left(s_{t}\right)$.

b) $\left(d_{1}^{*}, d_{2}^{*}\right) \in E^{c, o p}(G)$ if and only if either b1) or b2) holds:

b1) $\bar{Q} \leq d_{1}^{*}+d_{2}^{*}, \Pi_{1}^{2}\left(0, q_{M_{1}}\right)<\Pi_{2}^{2}\left(0, q_{M_{2}}\right)$, and $s_{t} \leq d_{1}^{*} \leq s_{t+1}$ for an even $t$,

b2) $\bar{Q} \leq d_{1}^{*}+d_{2}^{*}, \Pi_{1}^{2}\left(0, q_{M_{1}}\right)>\Pi_{2}^{2}\left(0, q_{M_{2}}\right)$, and $s_{t} \leq d_{1}^{*} \leq s_{t+1}$ for an odd $t$.

c) $\left(d_{2}^{*}, d_{1}^{*}\right) \in E^{c, o p}(G)$ if and only if either c1) or c2) holds:

c1) $\bar{Q} \geq d_{1}^{*}+d_{2}^{*}, \Pi_{1}^{2}\left(0, q_{M_{1}}\right)<\Pi_{2}^{2}\left(0, q_{M_{2}}\right)$, and $s_{t} \leq d_{2}^{*} \leq s_{t+1}$ for an odd $t$,

c2) $\bar{Q} \geq d_{1}^{*}+d_{2}^{*}, \Pi_{1}^{2}\left(0, q_{M_{1}}\right)>\Pi_{2}^{2}\left(0, q_{M_{2}}\right)$, and $s_{t} \leq d_{2}^{*} \leq s_{t+1}$ for an even $t$.

Remark: Note that in the case in which $d_{1}^{*}+d_{2}^{*}=\bar{Q}$, it may happen that $\left(d_{1}^{*}, d_{2}^{*}\right)$ or $\left(d_{2}^{*}, d_{1}^{*}\right)$ are equilibria. In these cases $d_{1}^{*}$ or $d_{2}^{*}$ coincide with the discontinuities of the reaction function $R_{o p}^{2}$.

The existence of equilibria cannot be guaranteed in this case either. Consider the following inverse demand functions: $p=60-30 q$ and $p=20-6 q$. It can be proven that there is no equilibrium. This case corresponds to the left-hand side of Figure 7.

Remark: For linear models it can be shown that the existence of an equilibrium can be guaranteed when $\Pi_{1}^{2}\left(0, q_{M_{1}}\right)<\Pi_{2}^{2}\left(0, q_{M_{2}}\right)$. The equilibrium is then $\left(2 c_{1}^{*}-\right.$ $\left.c_{2}^{*}, 2 c_{2}^{*}-c_{1}^{*}\right)$. This case is illustrated in the right-hand side of Figure 7 , where the demand functions in the scenarios $p=3-\frac{5}{2} q$, and $p=2-q$.

Moreover, under the initial assumptions, for linear models, the condition in Case a) of Theorem 6.5 does never hold, since the equilibria cannot belong to $L$. 

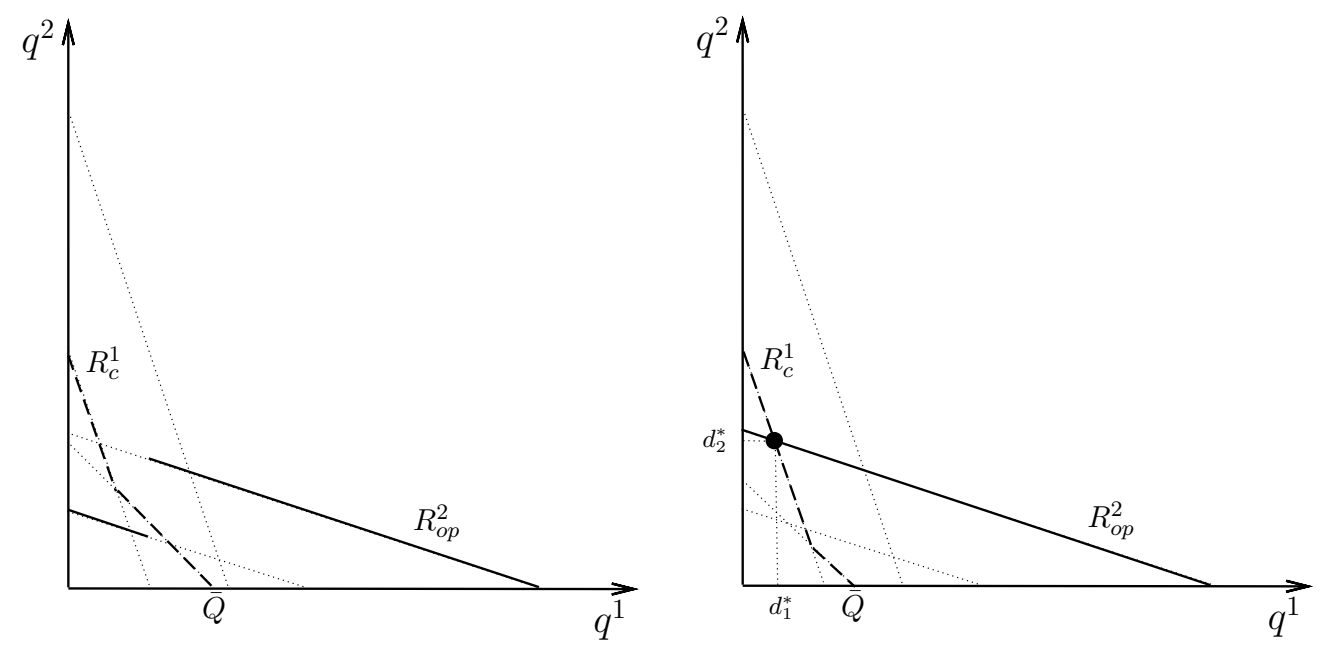

Figure 7: Cases of no equilibrium (left) and equilibrium (right) when Firm 1 is conservative and Firm 2 is optimistic.

\section{Conclusions}

In this paper, we have analysed the strategic decisions of firms in a context where there are two possible scenarios characterized by different demand functions. The firms have to decide their strategies on quantities before the uncertainty is resolved.

In an important preliminary step, the reaction functions of firms that exhibit extreme and neutral attitudes to uncertainty have been fully described. We have shown that under not very restrictive assumptions, the reaction for conservative firms is a continuous piece-wise function with, at most, three pieces. In the case of optimistic firms, the reaction function is also piece-wise. However, continuity cannot be assured.

The analysis of equilibria is carried out when firms show identical and different attitudes to uncertainty. In both cases, the presence of an optimistic firm implies that the existence of equilibria cannot be guaranteed. However, we establish necessary and sufficient conditions for the existence of equilibria and provide procedures to determine the sets of equilibria. If both firms are neutral, or one of them is neutral and the other one is conservative, equilibrium always exists and is unique. When both firms are conservative, existence is also assured, but multiple equilibria may exist. An important property of these equilibria is that, regardless of the scenario that finally occurs, all of them yield the same total output and price level. One interesting interpretation of these results is that, although crossing the price threshold by changing quantity causes a radical shift in the scenario in which the 
firms compete, when both firms are conservative there is a certain stabilization of equilibria; this does not occur when both firms are optimistic.

It is also worth remarking that, even though, when both firms are conservative and hence, firms are symmetric, non-symmetric conservative equilibria do exist. In fact, only one of the equilibria is symmetric. The consequence of the symmetry of the model is that the set of conservative equilibria is a symmetric set. This generalizes the result obtained by Caraballo et al. (2015) for linear models. Moreover, in linear models, when both firms are optimistic, equilibria always exist, while this cannot be assured for the general model.

Our analysis is valid for a broad range of concave inverse demand functions, which include among others, the special cases of linear and quadratic functions. However, our results have some limitations. For simplicity, and in order to avoid excessive technicalities, we have restricted our analysis to the case of two scenarios. Nevertheless, the ideas underlying our approach can also be used to describe the conservative, the optimistic and the neutral reaction functions in the cases of more than two scenarios, and therefore the corresponding equilibria could be identified. On the other hand, the analysis could be extended to more realistic situations in which firms do not exhibit extreme pessimistic or optimistic attitudes, and it is possible to characterize their behavior in terms of a parameter representing their degree of optimism. The influence of this optimism parameter on the equilibria outcomes is the topic of current research.

In addition, the research carried out in this paper extends the range of real-world situations where the ideas of Cournot competition can be applied. In fact, the study of situations where the attitudes of the firms towards uncertainty are not symmetric is particularly relevant since certain events can not only generate uncertainty about demand, but also lead firms to adopt different attitudes towards uncertainty. This would be the case, for example, of the results of parliamentary elections that can give rise to uncertainty about the demand for goods and services. In addition, the place where firms are located may influence their attitude towards uncertainty. If the elections are held in a country of the European Union, the attitudes towards uncertainty could depend on whether firms are settled inside or outside the Union.

Or let us think about the uncertain effects of the presidency of Donald Trump. The attitude towards the uncertainty of a Mexican firm may not be the same as that of an American firm.

Acknowledgements. The research of the authors is partially supported by the 
Andalusian Ministry of Economics, Innovation and Science, project P11-SEJ-7782 and by the Spanish Ministry of Economics and Competitiveness, Project ECO201568856-P (MINECO/FEDER) .

\section{Appendix}

Proof Lemma 3.1: Denote $\underline{L}=\left\{\left(q^{1}, q^{2}\right) \in \mathbb{R}^{2} \mid q^{1}+q^{2}<\bar{Q}\right\}$, and $\bar{L}=\left\{\left(q^{1}, q^{2}\right) \in\right.$ $\left.\mathbb{R}^{2} \mid q^{1}+q^{2}>\bar{Q}\right\}$. Recall that for each firm, the profit functions in the scenarios, $\Pi_{1}$ and $\Pi_{2}$, are concave at its own action. When firm $j$ selects a strategy $q^{j}$ such that $\bar{Q}-q^{j} \leq r_{1}^{i}\left(q^{j}\right) \leq r_{2}^{i}\left(q^{j}\right)$, then $\left(r_{1}^{i}\left(q^{j}\right), q^{j}\right) \in \bar{L}$ and $\left(r_{2}^{i}\left(q^{j}\right), q^{j}\right) \in \bar{L}$. Since, at $\bar{L}$ the value function coincides with the profits in scenario $1, \Pi_{c}=\Pi_{1}$, then the conservative firm $i$ will select $r_{1}^{i}\left(q^{j}\right)$ as the best response.

Analogously, if firm $j$ selects a strategy $q^{j}$ such that $r_{1}^{i}\left(q^{j}\right) \leq r_{2}^{i}\left(q^{j}\right) \leq \bar{Q}-q^{j}$, then $\left(r_{1}^{i}\left(q^{j}\right), q^{j}\right) \in \underline{L}$, and $\left(r_{2}^{i}\left(q^{j}\right), q^{j}\right) \in \underline{L}$. Since, at $\underline{L}$ the value function of the firm coincides with the profit in scenario $2, \Pi_{c}=\Pi_{2}$, then the conservative firm $i$ will select $r_{2}^{i}\left(q^{j}\right)$ as the best response.

If firm $j$ selects a strategy $q^{j}$ such that $r_{1}^{i}\left(q^{j}\right) \leq \bar{Q}-q^{j} \leq r_{2}^{i}\left(q^{j}\right)$, then $\left(r_{1}^{i}\left(q^{j}\right), q^{j}\right) \in$ $\underline{L}$ and $\left(r_{2}^{i}\left(q^{j}\right), q^{j}\right) \in \bar{L}$. Note that at $\underline{L}, \Pi_{c}=\Pi_{2}$. If firm $i$ chooses a strategy $q^{i}$ such that $\left(q^{i}, q^{j}\right) \in \underline{L}$, then the firm should select this quantity as large as possible since $\Pi_{c}$ increases with $q^{i}$. However, once $\left(q^{i}, q^{j}\right) \in \bar{L}$, then $\Pi_{c}=\Pi_{1}$, and $\Pi_{c}$ decreases as $q^{i}$ increases. As a result, the best response for a conservative firm $i$ is to choose the strategy such that $\left(q^{i}, q^{j}\right) \in L$, that is $q^{i}=\bar{Q}-q^{j}$.

Proof Lemma 3.2: By using a reasoning analogous to that of the Lemma 3.1, it is easy to see that, given a strategy of firm $j, q^{j}$, if both $\left(r_{1}^{i}\left(q^{j}\right), q^{j}\right)$ and $\left(r_{2}^{i}\left(q^{j}\right), q^{j}\right)$ belong to either $\underline{L}$ or $\bar{L}$, then firm $i$ will select the best response at the scenario which corresponds to the optimistic option in $\underline{L}$ or $\bar{L}$.

Proof Lemma 3.4: Consider $q^{j} \in A^{j}$ and $q^{i}=R_{n}^{i}\left(q^{j}\right), j=1,2, j \neq i$. Suppose that $q^{i}=R_{n}^{i}\left(q^{j}\right)<r_{1}^{i}\left(q^{j}\right)<r_{2}^{i}\left(q^{j}\right)$. Since the profit functions at the scenarios $\Pi_{1}^{i}$ and $\Pi_{2}^{i}$ are stricly concave in its own actions and they attains their maximun value at $r_{1}^{i}\left(q^{j}\right)$ and $r_{2}^{i}\left(q^{j}\right)$, respectively, then $\Pi_{1}^{i}\left(q^{i}+\varepsilon, q^{j}\right)>\Pi_{1}^{i}\left(q^{i}, q^{j}\right)$ and $\Pi_{2}^{i}\left(q^{i}+\varepsilon, q^{j}\right)>\Pi_{2}^{i}\left(q^{i}, q^{j}\right)$, for $\varepsilon>0$. Therefore, $\Pi_{n}^{i}\left(q^{i}+\varepsilon, q^{j}\right)>\Pi_{n}^{i}\left(q^{i}, q^{j}\right)$ and $q^{i}$ is not the best response to $q^{j}$. Analogously, suppose that $r_{1}^{i}\left(q^{j}\right)<r_{2}^{i}\left(q^{j}\right)<q^{i}=R_{n}^{i}\left(q^{j}\right)$. In this case, $\Pi_{1}^{i}\left(q^{i}-\varepsilon, q^{j}\right)>\Pi_{1}^{i}\left(q^{i}, q^{j}\right)$ and $\Pi_{2}^{i}\left(q^{i}-\varepsilon, q^{j}\right)>\Pi_{2}^{i}\left(q^{i}, q^{j}\right)$, for $\varepsilon>0$. Therefore, $\Pi_{n}^{i}\left(q^{i}-\varepsilon, q^{j}\right)>\Pi_{n}^{i}\left(q^{i}, q^{j}\right)$ and $q^{i}$ is not the best response to $q^{j}$. Hence, if $q^{i}=R_{n}^{i}\left(q^{j}\right)$, 
then $r_{1}^{i}\left(q^{j}\right) \leq R_{n}^{i}\left(q^{j}\right) \leq r_{2}^{i}\left(q^{j}\right)$.

Proof Lemma 4.2: In order to prove that $E^{u}(G) \subseteq T$, suppose on the contrary that $\left(\bar{q}^{1}, \bar{q}^{2}\right) \notin T$ and $\left(\bar{q}^{1}, \bar{q}^{2}\right) \in E^{u}(G)$. If $\bar{q}^{1}<r_{1}^{1}\left(\bar{q}^{2}\right)$, since each firm's objective function, $\Pi_{k}^{i}$, is strictly concave in the firm's own quantity, both $\Pi_{1}^{1}\left(q^{1}, \bar{q}^{2}\right)$ and $\Pi_{2}^{1}\left(q^{1}, \bar{q}^{2}\right)$ are increasing for $q^{1} \leq r_{1}^{1}\left(\bar{q}^{2}\right)$, therefore, it follows that if firm 1 moves to $\bar{q}^{1}+\varepsilon$ then his profit will increase in both scenarios and thus $\Pi_{u^{1}}$ will increase. Hence, $\left(\bar{q}^{1}, \bar{q}^{2}\right) \notin E^{u}(G)$. Analogously, this can be proven for $\bar{q}^{1}>r_{2}^{1}\left(\bar{q}^{2}\right)$, for $\bar{q}^{2}<r_{1}^{2}\left(\bar{q}^{1}\right)$ and for $\bar{q}^{2}>r_{2}^{2}\left(\bar{q}^{1}\right)$.

Proof Theorem 5.1: We first prove that $T \cap L \subseteq E^{c}(G)$.

A point $\left(q^{1}, q^{2}\right) \in E^{c}(G)$, if and only if $\left(q^{1}, R_{c}^{2}\left(q^{1}\right)\right)=\left(R_{c}^{1}\left(q^{2}\right), q^{2}\right)$. If $\left(q^{1}, q^{2}\right) \in$ $T \cap L$, then it follows from Lemma 3.1 that $R_{c}^{1}\left(q^{2}\right)=\bar{Q}-q^{2}$ and $R_{c}^{2}\left(q^{1}\right)=\bar{Q}-q^{1}$, and therefore, since $\left(q^{1}, \bar{Q}-q^{1}\right)=\left(\bar{Q}-q^{2}, q^{2}\right)$, the point is a conservative equilibrium.

We next prove that if $\left(q^{1}, q^{2}\right) \in E^{c}(G)$ then either $\left(q^{1}, q^{2}\right) \in T \cap L$ or $\left(q^{1}, q^{2}\right)$ coincides with the Cournot equilibrium in one of the scenarios.

Suppose that $\left(q^{1}, q^{2}\right) \in E^{c}(G)$ and $\left(q^{1}, q^{2}\right) \in T \cap \underline{L}$. Consider first the points in the interior of $T, \operatorname{int}(T)$. Let $\left(q^{1}, q^{2}\right) \in \operatorname{int}(T) \cap \underline{L}$. Since $\underline{L}$ is an open set and $q^{2}<r_{2}^{1}\left(q^{1}\right)$, for $\varepsilon>0$, then $\left(q^{1}, q^{2}+\varepsilon\right) \in \operatorname{int}(T) \cap \underline{L}$. At $\underline{L}, \Pi_{c}\left(q^{1}, q^{2}\right)=$ $\Pi_{2}\left(q^{1}, q^{2}\right)$, and it follows from the strict concavity in its own action of $\Pi_{2}$ that $\Pi_{c}\left(q^{1}, q^{2}+\varepsilon\right)>\Pi_{c}\left(q^{1}, q^{2}\right)$. Therefore, $\left(q^{1}, q^{2}\right) \notin E^{c}(G)$. An analogous reasoning holds when $\left(q^{1}, q^{2}\right) \in \operatorname{int}(T) \cap \bar{L}$.

Now consider the points on the boundary of $T, \partial T$. Note that these points are located on the graphs of some of the reaction functions. Let $\left(q^{1}, q^{2}\right) \in \partial T \cap \underline{L}$. At $\underline{L}$, $\Pi_{c}\left(q^{1}, q^{2}\right)=\Pi_{2}\left(q^{1}, q^{2}\right)$, Therefore, for $\left(q^{1}, q^{2}\right)$ to be a conservative equilibrium $\left(q^{1}, q^{2}\right)$ needs to be the Cournot equilibrium in scenario 2. Analogously, when $\left(q^{1}, q^{2}\right) \in$ $\partial T \cap \bar{L}$, if $\left(q^{1}, q^{2}\right)$ is a conservative equilibrium, then this point must be the Cournot equilibrium in scenario 1 .

Cases a) and c): If $\bar{Q}<2 c_{1}^{*}$ then $\left(c_{1}^{*}, c_{1}^{*}\right) \in \bar{L}$. Since for $\left(q^{1}, q^{2}\right) \in \bar{L}, \Pi_{c}\left(q^{1}, q^{2}\right)=$ $\Pi_{1}\left(q^{1}, q^{2}\right)$, it is easy to see that the Cournot equilibrium of scenario 1 is also a conservative equilibrium. If $\bar{Q}=2 c_{1}^{*}$, then $T \cap L=\left\{\left(c_{1}^{*}, c_{1}^{*}\right)\right\}$ and it follows that $E^{c}(G)=\left\{\left(c_{1}^{*}, c_{1}^{*}\right)\right\}$. The proof of case c) is analogous.

Case b) If $2 c_{1}^{*}<\bar{Q}<2 c_{2}^{*}$ then $T \cap L \neq\{\emptyset\}$, and $T \cap L \subseteq E^{c}(G)$. Moreover, $\left(c_{1}^{*}, c_{1}^{*}\right)$ cannot be a conservative equilibrium, since in this case $\left(c_{1}^{*}, c_{1}^{*}\right) \in \underline{L}, \Pi_{c}\left(c_{1}^{*}, c_{1}^{*}\right)=$ $\Pi_{2}\left(c_{1}^{*}, c_{1}^{*}\right)$, and therefore the firms can improve their conservative value function by adopting a strategy $q^{i}>c_{1}^{*}$. Analogously, $\left(c_{2}^{*}, c_{2}^{*}\right)$ cannot be a conservative equilibrium, and the result follows. 
Proof Theorem 5.4: The result follows from Lemmas 3.3 and 5.2.

Proof Theorem 6.1: The existence of equilibria follows from the fact that the value functions of the neutral firm and the value function of the conservative firm are concave in its own action.

If $\bar{Q} \geq z_{2}^{* 1}+z_{2}^{* 2}$ then, it follows from Lemma 3.1 that $R_{c}^{2}\left(z_{2}^{* 1}\right)=r_{2}^{2}\left(z_{2}^{* 1}\right)=z_{2}^{* 2}$. Thus, $\left(z_{2}^{* 1}, z_{2}^{* 2}\right)$ is an equilibrium. Conversely, if $\left(z_{2}^{* 1}, z_{2}^{* 2}\right)$ is an equilibrium, then $R_{c}^{2}\left(z_{2}^{* 1}\right)=r_{2}^{2}\left(z_{2}^{* 1}\right)$ and, from Lemma $3.1, \bar{Q} \geq z_{2}^{* 1}+z_{2}^{* 2}$ holds.

To prove uniqueness, note that the reaction function of the neutral firm is strictly decreasing and continuously differentiable and its derivative fulfills $\left(R_{n}^{1}\right)^{\prime}\left(q^{2}\right)>-1$ in the interval where it attains positive values. On the other hand, the reaction function of the conservative firm is a piecewise function, strictly decreasing and continuous. It is also differentiable, except at most at two points. Where differentiable, it fulfills $\left(R_{c}^{1}\right)^{\prime}\left(q^{1}\right) \geq-1$.

Let $\bar{Z}_{2}=z_{2}^{* 1}+z_{2}^{* 2}$. Since $\left(R_{n}^{1}\right)^{\prime}\left(q^{2}\right)>-1$, for all the points of the graph $\left(R_{n}^{1}\left(q^{2}\right), q^{2}\right)$ with $q^{2}<z_{2}^{* 2}$, then $R_{n}^{1}\left(q^{2}\right)+q^{2}<\bar{Z}_{2}$ holds. If the graphs of the reaction functions, $R_{n}^{1}$ and $R_{c}^{2}$, intersect at any other point $\left(q^{1}, q^{2}\right)$, then $q^{2}=R_{c}^{2}\left(q^{1}\right)=\bar{Q}-q^{1}$ or $q^{2}=R_{c}^{2}\left(q^{1}\right)=r_{1}^{2}\left(q^{1}\right)$ must hold. In both cases, by using Lemma 3.1, $q^{1}+q^{2} \geq$ $\bar{Q} \geq \bar{Z}_{2}$ what contradicts $R_{n}^{1}\left(q^{2}\right)+q^{2}<\bar{Z}_{2}$.

Cases b) and c) can be proven by using analogous reasonings.

Proof Lemma 6.4: If an equilibrium exists in $\bar{L}$, then the reaction functions of both firms must intersect on $\bar{L}$. From Lemma 3.1, it can be assured that in $\bar{L}$, the conservative reaction function corresponds to $r_{1}^{1}$. From Lemma 3.2, the optimistic reaction function corresponds to $r_{2}^{2}$. Therefore, only $\left(d_{1}^{*}, d_{2}^{*}\right)$ can be an equilibrium. The same reasoning applies if a equilibrium exists in $\underline{L}$. In this case, only $\left(d_{2}^{*}, d_{1}^{*}\right)$ can be an equilibrium. If an equilibrium exists in $L$, Lemma 3.1 assures that the reaction function of the conservative firm is defined by $\bar{Q}-q^{2}$. The optimistic response may correspond to $r_{1}^{2}$ or $r_{2}^{2}$, and therefore only if $\bar{Q}-q^{2}=s_{t}$, where $s_{t}$ corresponds to a discontinuity of $R_{o p}^{2}$, an equilibrium in $L$ can exist.

Proof Theorem 6.5: It follows from Lemma 6.4 and a similar reasoning to Theorem 6.1 


\section{References}

Asplund M., 2002. Risk-averse firms in oligopoly. International Journal of Industrial Organization 20, 995-1012.

Caraballo MA., Mármol AM., Monroy L., Buitrago E., 2015. Cournot competition under uncertainty. Conservative and optimistic equilibria. Review of Economic Design 19, 145-165.

Chronopoulos M., De Reyck B., Siddiqui A., 2014. Duopolistic competition under risk aversion and uncertainty. European Journal of Operational Research 236, 643656 .

Cournot AA., 1838. Recherches sur les principles mathematiques de la theorie des richesses. Hachette, Paris.

de Frutos MA., Fabra N., 2011. Endogenous capacities and price competition: the role of demand uncertainty. International Journal of Industrial Organization 29, 399-411.

Eichberger J., Kelsey D., 2002. Strategic complements, substitutes, and ambiguity: the implications for public goods. Journal of Economic Theory 106, 436466.

Eichberger J., Kelsey D., Schipper B.C., 2009. Ambiguity and social interaction Oxford Economic Papers, 61, 355-379.

Einy E., Haimanko O., Moreno D., Shitovitz B., 2010. On the existence of Bayesian Cournot equilibrium. Games and Economic Behavior 68, 77-94.

Fontini F., 2005. Cournot oligopoly under strategic uncertainty with optimistic and pessimistic firms. Metroeconomica 56, 318-333.

Gal-Or E., 1986. Information transmission-Cournot and Bertrand equilibria. Review of Economic Studies, 53, 85-92.

Gilboa I., Schmeidler D., 1989. Maxmin expected utility with non-unique prior. Journal of Mathematical Economics 18, 141-153.

Kreps DM., Scheinkman JA., 1983. Quantity precommitment and Bertrand competition yield Cournot outcomes. The Bell Journal of Economics 14, 326-337.

Lagerlöf JMN., 2007. Insisting on a non-negative price: oligopoly, uncertainty, welfare, and multiple equilibria. International Journal of Industrial Organization $25,861-875$

Lepore JJ., 2012. Cournot outcomes under Bertrand-Edgeworth competition with demand uncertainty. Journal of Mathematical Economics 48, 177-186. 
Li L., 1985. Cournot Oligopoly with Information Sharing. The RAND Journal of Economics 16, 521-53

Mármol AM., Monroy L., Caraballo MA., Zapata A., 2016. Equilibria with vectorvalued utilities and preference information. The analysis of a mixed duopoly. Mimeo, available at ssrn.com/abstract $=2836905$.

Monroy L., Caraballo MA., Mármol AM. Zapata A., 2016. Agents with otherregarding preferences in the commons. Metroeconomica DOI 10.1111/meca.12158. Nash J., 1951. Non-cooperative games. Annals of Mathematics 54(2), 286-295.

Novshek W., Sonnenschein H., 1982. Fulfilled expectations Cournot duopoly with information acquisition and release. Bell Journal of Economics 13, 214-218.

Roberts J., Sonnenschein H., 1976. On the existence of Cournot equilibrium without concave profit functions. Journal of Economic Theory 13, 112-117.

Savage L. 1954. The Foundations of Statistics. Wiley, New York.

Schmeidler D., 1989. Subjective probability and expected utility without additivity. Econometrica 57,571587.

Vives X., 1984. Duopoly information equilibrium: Cournot and Bertrand. Journal of Economic Theory 34, 71-94.

Wu J., Zhai X., Huang Z., 2008. Incentives for information sharing in duopoly with capacity constraints. Omega 36, 963-975. 